spent on arms would make vast health improvement possible'. A representative of UNICEF commented on how continued increase of poverty in the Third World involved a threat of causing the explosive situation which could set off nuclear war.

(3) Jeff Clymow writes (The Guardian, 7 November 1985): 'People have undertaken mass protest against the arms race since 1908 at least, and there has not been one single step backwards. Alas for the apolitical of this country, nuclear arms reductions will occur only as a result of political decisions carried out by governments elected for that purpose among others. It is naive and foolish to expect otherwise'. Is this true and, if so, do we understand its implications?

I have picked out those three issues as being areas where the experience and expertise of our psychiatric colleagues could be of genuine value to the peace movement if more of our number who are knowledgeable in the operation of mental and emotional forces would come out in the open to shed light on those urgent considerations. Is this asking too much of a profession dedicated to mental health?

Uffculme Clinic,

DAVID T. MACLAY

Birmingham

\section{ECT with music: Historical perspective}

DeAr Sirs

I was interested to read of the endeavours of Drs Almeida and Tapang in providing music during ECT (letter to Bulletin. December 1985, 9, 251). A veil of déjà entendu descended upon me as I recalled my own use of music during ECT in a day hospital in Perth. Western Australia as far back as 1959. Further reverie led me back to more uncertain memories of using music during ECT whilst I was Registrar and Senior Registrar at Middlewood Hospital, Sheffield in 1955. Since it is unlikely that I was a true innovator there must have been others employing music during ECT sessions so that the discovery of any literature on the subject may require searches back to this period.

The reason for music during ECT was not merely aesthetic nor even that it had a calming effect on the patients whilst waiting for treatment or recovering from it. I remember clearly that one of the reasons was to mask unpleasant or frightening sounds emanating from the next bed. You must remember that in those days ECT was the only effective treatment for depression and was still being used for some patients with schizophrenia so that large numbers of patients had to be treated at each session, figures of 20 to 25 being not at all unusual. It was therefore customary practice to use a large room or ward with screens between the beds and to have all the patients waiting in their beds as the treatment team moved 'along the line'.

Although its primary aim was to mask worrying noises coming from other patients being treated, it was also thought that music would be soothing, particularly for those waiting for their turn. Certainly in Perth I developed this idea somewhat and I remember we even had request programmes! Patients waiting in their beds for treatment were calm and relaxed which must have favoured the anaesthetic procedure.

I cannot remember precisely whether there was less anxiety recovering from ECT and anaesthesia but I would have thought that music might well fix the attention of semi-confused patients until they were more fully orientated. This should be particularly so since it is said that auditory perception is the last sense to disappear and the first to reappear during the induction and recovery phases of anaesthesia.

Central Hospital

ROGER WHITELEY

Warwick

\section{ECT and the Media}

\section{DeAr Sirs}

I read Dr Hodgkinson's letter (Bulletin, February 1986, 10, 37) with interest. He wrote about the 'devastating' future effect which Disney's $O z$ films may have on patients requiring ECT. In 1982 a questionnaire-based survey was conducted on a lay sample $(\mathrm{N}=100)$ to elicit their attitudes to, and experiences of, ECT. ${ }^{1}$ The results indicated lay hostility to ECT, a receptivity to adverse publicity, a tendency not to question such adversity, and a proneness to blame all ills on ECT. A particularly influential source of such 'information' was the film One Flew over the Cuckoo's Nest. Briefly, 61 per cent had seen the film; 65.6 per cent of these had been 'put off ECT' by the film. Only 10 viewers, or 16.4 per cent of those who saw it, reported neutral effects on their attitudes to ECT. Our respondents, as suggested in Dr Hodgkinson's letter, imagined that some pretty terrific sequelae were the usual legacy of this treatment.

I gave up talking to newspapers about ECT when one reporter entitled his piece 'That pain went right through my head'. ${ }^{2}$ The content of the article bore little connection to my actual words. The article was captioned by a drawing of a distraught girl with her incisors missing!

More recently, in my own hospital, I discovered that some nurses felt uneasy about talking to patients and relatives about ECT. They were unsure of their ability to answer probing questions. At their request I wrote a short piece for the hospital monthly. ${ }^{3}$ The feedback has been encouraging.

Newcastle Hospital, Greystones,

BruN O'ShEA

Co. Wicklow

REFERENCES

'O'SheA, B., MCGannas, A. (1983) ECT: lay attitudes and experiences-a pilot study. Irish Medical Journal, 76, 40-43.

${ }^{2}$ MuLER, B. (1983) 'That pain went right through my head'. Inside Tribune, April 24, p. 13.

${ }^{3}$ O'SHEA, B. (1986) ECT: what is it? Anchor, No. 12. 